\title{
IMKB'de İşlem Gören Aracı Kuruluş Varantları için Etkin Fiyatlama Modelinin Belirlenmesi
}

\author{
Determination of Efficient Pricing Model for The Warrants Listed on The ISE
}

Rıfat KARAKUŞ ${ }^{1}$, İsrafil ZOR ${ }^{2}$

\begin{abstract}
ÖZET
Bu çalışmada, iMKB'de işlem gören aracı kuruluş varantları için hangi fiyatlama modelinin etkin olduğunun belirlenmesi amaçlanmıştır. 2012 yılında işlem gören, IMKB-30 endeksine dayalı 61 alım varantına ait 3,000'den fazla gözlem kullanılarak Black-Scholes, Black-Scholes-Merton, Varyansın Sabit Esnekliği (Karekök Modeli) ve Binomial modeller ile hesaplanan günlük varant fiyatlarının piyasa fiyatından farkılış̧maları dikkate alınarak test edilmiştir. Karda/zararda olma durumlarına göre 3 gruba ayrılan varantlar için modellerden elde edilen fiyatlar ile piyasa fiyatlarının istatistiksel olarak farklılaşması bağımsız t testi kullanılarak tespit edilmiştir. Çalışma sonucunda karda olan varantlar için Black-Scholes-Merton modeli etkin model olarak belirlenirken, başabaş ve zararda olan varantlar için Black-Scholes modeli ile Black-Scholes-Merton modelleri arasında kararsız kalınmıştır.
\end{abstract}

Anahtar Kelimeler: Varant, opsiyon fiyatlama modelleri, IMKB.

\section{GíRiş}

Varant, belirli bir tarihte belirli bir fiyattan varantı ihraç eden şirketin hisse senedini alma hakkı veren opsiyon olarak tanımlanmaktadır. Tanımda yer alan bazı üstü kapalı unsurların değişkenlik göstermesi mümkündür. Kullanım fiyatının belirlenen ara dönemlerde revize edilebilmesi, ihraççı şirket tarafından varantın vadesinin uzatılabilmesi veya vadesinden önce çağrılabilmesi değişkenlik gösteren bu unsurların temel örnekleridir (Mayo, 2010, s.708).

Türkiye'de varantların Borsa'ya kotasyonu ve işlem görmesine ilişkin usul ve esaslar 05.01.2010 tarih ve 318 sayılı IMKB Genelgesi ile düzenlenmiş ve varantlar 2010 yılından itibaren işlem görmeye başlamıştır. Aracı kuruluşlar tarafından ihraç edilerek piyasada işlem görmeye başlayan varantlar, temel bazı özellikleri taşımaması ile diğer ülkelerde işlem görenlerden farklılaşmaktadır. ìlk olarak, varantların dayanak varlığı oluşturan hisse senedinin ait olduğu şirket tarafından değil, aracı kuruluşlar tarafından ihraç edilmeleri, nakdi uzlaşıyı ve varantın va-

\begin{abstract}
The aim of the study is to determine the efficient pricing model for the warrants traded on the ISE. By using more than 3.000 observations about the call warrants that's underlying security is ISE-30 Index and traded in 2012, Black-Scholes, BlackScholes-Merton, Square Root Constant Elasticity Variance and Binomial models are tested according to difference between model and market prices. Also independent $t$ test is used to explain the statistical efficiency of differences between model and market prices for warrants that are grouped according to their moneyness degree. As a result of the study, BlackScholes-Merton model is the most efficient model for in-themoney warrants, but it is not possible to choose one of the models that are Black-Scholes and Black-Scholes-Merton for at-the-money and out-of-money warrants.
\end{abstract}

Keywords: Warrant, option pricing models, ISE.

desinde karda olması durumunda şirket tarafından yeni hisse senetleri ihraç edilerek sulandırma etkisi yapmamasını beraberinde getirmektedir (Kolb, 1995:316). Türkiye piyasaları için yeni bir türev ürün olan varantların likiditesini sağlamak amacıyla piyasa yapıcılı bir mekanizma oluşturulması, fiyatlamada sınırlamalara neden olmaktadır. Varantların yedi yıla kadar vade taşıdığı örneklerle karşılaştırıldığında aracı kuruluş varantlarının kısa vadelere sahip olduğu söylenebilir. Yine bazı varant sözleşmelerinde yer bulabilen vade tarihinin uzatılması veya vadeden önce çağrılma seçenekleri uygulamada mümkün olmayan özelliklerdir.

Opsiyonların değerlenmesinde kullanılan ve literatürde yoğunlukla yer bulan modeller; Black-Scholes Modeli, Black-Scholes-Merton Modeli , Varyansın Sabit Esnekliği (Karekök Modeli) Modeli ve Binomial Modeli'dir. Literatürde, opsiyonların değer tespitine ilişkin farklı varsayımlara dayanan farklı fiyatlama modelleri bulunması, hangi modelin ilgili piyasa için daha etkin' olduğunun belirlenmesi ihtiyacını ortaya çıkarmaktadır. Belirtilen bu ihtiyacı gidermek amacıyla 
Türkiye dışındaki piyasalarda işlem gören varantlara ait fiyatların hangi modellerle açıklanabileceğini test eden çalışmalar mevcut iken Türkiye'de bu ihtiyacı giderecek bir çalışmaya rastlanılmamıştır. Türkiye piyasası için yeni bir finansal enstrüman olan varantların fiyatlanması için etkin yöntemi belirlemeye yönelik henüz yapılmış çalışma bulunmaması, bu çalışmanın yapılmasında en önemli isteklendirici unsur olmuştur. Çalışmanın ilerleyen bölümlerinde önce literatür taramasına yer verilmiş, opsiyon fiyatlama modelleri açıklanmış, sonra da ampirik bir uygulama ile etkin modelin tespiti yapılmıştır.

\section{LITERATÜR TARAMASI}

Varant fiyatlamasında hangi opsiyon fiyatlama modelinin daha etkin olduğuna ilişkin çalışmalar genellikle Amerikan şirketleri tarafından ihraç edilen varantlar üzerinde yoğunlaşmasına (Noreen ve Wolfson, 1981; Lauterbach ve Schultz, 1990; Hauser ve Lauterbach, 1997) rağmen diğer ülke şirket varantları için de yapılmış çalışmalar (Frino vd. 1991; Kuwahara ve Marsh, 1992; Shastri ve Sirodom, 1995; Santoso, 2000; Boonchuaymetta ve Treerapot, 2007; Jianfeng vd. 2011) bulunmaktadır. Literatürde yer alan çalışmalara ait örnek kütleler, yöntemler ve sonuçlar aşağıda (Tablo 1) özet bir şekilde sunulmaktadır.

Tablo 1: Literatür Taraması

\begin{tabular}{|c|c|c|c|c|}
\hline $\begin{array}{l}\text { Çalışmayı } \\
\text { Yapan/ } \\
\text { Yapanlar }\end{array}$ & Örnek Kütle & $\begin{array}{l}\text { Karşılaştırılan } \\
\text { Modeller }\end{array}$ & Yöntem & Sonuç \\
\hline $\begin{array}{l}\text { Noreen ve } \\
\text { Wolfson (1981) }\end{array}$ & $\begin{array}{l}\text { New York ve Amerika } \\
\text { Menkul Kıymetler } \\
\text { Borsaları'nda 1968-1978 } \\
\text { yılları arasında işlem gören } \\
52 \text { varant }\end{array}$ & $\begin{array}{l}\text { Sulandırma Etkisi } \\
\text { Dahil Edilmiş BS ve } \\
\text { Sulandırma Etkisi } \\
\text { Dahil Edilmiş SRCEV }\end{array}$ & t testi & $\begin{array}{l}\text { Modellerin farklılaşmadığı sonucuna } \\
\text { varılmıştır. }\end{array}$ \\
\hline $\begin{array}{l}\text { Lauterbach ve } \\
\text { Schultz (1990) }\end{array}$ & $\begin{array}{l}\text { New York ve Amerika } \\
\text { Menkul Kıymetler } \\
\text { Borsaları'nda 1971-1980 } \\
\text { yılları arasında işlem gören } \\
39 \text { varant }\end{array}$ & $\begin{array}{l}\text { Sulandırma Etkisi } \\
\text { Dahil Edilmiş BS ve } \\
\text { Sulandırma Etkisi } \\
\text { Dahil Edilmiş SRCEV }\end{array}$ & t testi & $\begin{array}{l}\text { SRCEV modelinin BS modeline göre daha } \\
\text { etkin olduğu tespit edilmiştir. }\end{array}$ \\
\hline $\begin{array}{l}\text { Frino vd. } \\
\text { (1991). }\end{array}$ & $\begin{array}{l}\text { Avustralya Opsiyon } \\
\text { Piyasasında } 1990 \text { yılında } \\
\text { işlem gören } 29 \text { varant }\end{array}$ & BS & $\begin{array}{l}\text { Wilcoxon } \\
\text { İşaretli } \\
\text { Sıralar Testi, } \\
\text { Spearman } \\
\text { Sıralama } \\
\text { Korelasyon } \\
\text { Katsayısı }\end{array}$ & $\begin{array}{l}\text { BS modelinin Avustralya piyasası için } \\
\text { etkin olduğunu ortaya koymuştur. }\end{array}$ \\
\hline $\begin{array}{l}\text { Kremer ve } \\
\text { Roenfeldt } \\
\text { (1993) }\end{array}$ & $\begin{array}{l}\text { New York ve Amerika } \\
\text { Menkul Kıymetler } \\
\text { Borsaları'nda 1981-1985 } \\
\text { yılları arasında işlem gören } \\
75 \text { varant }\end{array}$ & $\begin{array}{l}\text { Sulandırma Etkisi } \\
\text { Dahil Edilmiş BS ve } \\
\text { Sulandırma Etkisi } \\
\text { Dahil Edilmiş Sıçrama } \\
\text { Difüzyon (Jump- } \\
\text { Diffusion) Modeli }\end{array}$ & t testi & $\begin{array}{l}\text { Genellikle BS modelinin daha etkin } \\
\text { olduğu, zararda varantlar ile tarihsel } \\
\text { olarak büyük ve/veya sık sıçramalara } \\
\text { sahip hisse senetlerine dayanan varantlar } \\
\text { için Sıçrama Difüzyon Modelinin tercih } \\
\text { edilebileceği sonucuna varılmıştır. }\end{array}$ \\
\hline $\begin{array}{l}\text { Shastri ve } \\
\text { Sirodom (1995) }\end{array}$ & $\begin{array}{l}\text { Tayland Menkul Kıymetler } \\
\text { Borsası'nda } 1992 \text { yılında } \\
\text { işlem gören } 4 \text { hisse senedini } \\
\text { dayanak alan varantlar }\end{array}$ & $\begin{array}{l}\text { Sulandırma Etkisi } \\
\text { Dahil Edilmiş BS ve } \\
\text { SRCEV }\end{array}$ & $\begin{array}{l}\text { t testi ve } \\
\text { Wilcoxon } \\
\text { İşaretli } \\
\text { Sıralar Testi }\end{array}$ & $\begin{array}{l}\text { Her iki modele göre de karda varantların } \\
\text { düşük, zararda varantların yüksek } \\
\text { fiyatlandığı ve SRCEV modelinin daha } \\
\text { etkin olduğuna ulaşılmıştır. }\end{array}$ \\
\hline $\begin{array}{l}\text { Roon ve Veld } \\
\text { (1996) }\end{array}$ & $\begin{array}{l}\text { Amsterdam Menkul } \\
\text { Kıymetler Borsası'nda 1992- } \\
1993 \text { yılları arasında işlem } \\
\text { gören DAX, CAC } 40 \text { ve FT-SE } \\
100 \text { endekslerini dayanak } \\
\text { alan varantlar }\end{array}$ & $\begin{array}{l}\text { BS (DAX için), BSM } \\
\text { (CAC } 40 \text { ve FT-SE } 100 \\
\text { için) ve SRCEV }\end{array}$ & * & $\begin{array}{l}\text { Model sonuçlarının farklılaşmadığı } \\
\text { ve CAC-40 ve FT-SE } 100 \text { endekslerini } \\
\text { dayanak alan varantların düşük, DAX } \\
\text { endeksini dayanak alan varantların ise } \\
\text { yüksek fiyatlandığı tespit edilmiştir. }\end{array}$ \\
\hline $\begin{array}{l}\text { Chen vd. } \\
\text { (1997) }\end{array}$ & $\begin{array}{l}\text { Londra Menkul Kıymetler } \\
\text { Borsası'nda 1990-1991 yılları } \\
\text { arasında işlem gören FT-SE } \\
100 \text { Endeksini dayanak alan } \\
\text { varantlar }\end{array}$ & $\begin{array}{l}\text { Dravid-Richardson- } \\
\text { Son Modeli ve SRCEV }\end{array}$ & t testi & $\begin{array}{l}\text { Her iki modelin de yüksek etkinliğe sahip } \\
\text { olduğu sonucuna varılmıştır. }\end{array}$ \\
\hline
\end{tabular}


Tablo 1 (Devamı)

\begin{tabular}{|c|c|c|c|c|}
\hline $\begin{array}{l}\text { Hauser ve } \\
\text { Lauterbach } \\
\text { (1997) }\end{array}$ & $\begin{array}{l}\text { New York ve Amerika } \\
\text { Menkul Kıymetler } \\
\text { Borsaları'nda 1971-1980 } \\
\text { yılları arasında işlem gören } \\
29 \text { varant }\end{array}$ & $\begin{array}{l}\text { BS, Sulandırma Etkisi } \\
\text { Dahil Edilmiş BS, } \\
\text { Longstaff Uzatılabilir } \\
\text { Varant, SRCEV ve } \\
\text { Varyansın Sabit } \\
\text { Esnekliği Serbest Teta } \\
\text { Modelleri }\end{array}$ & t testi & $\begin{array}{l}\text { Varyansın Sabit Esnekliği Modellerinin } \\
\text { diğer modellere göre daha üstün olduğu } \\
\text { sonucuna varılmıştır. }\end{array}$ \\
\hline Santoso (2000) & $\begin{array}{l}\text { Jakarta Menkul Kıymetler } \\
\text { Borsası'nda 1997-2000 yılları } \\
\text { arasında işlem gören } 10 \\
\text { varant }\end{array}$ & $\begin{array}{l}\text { BSM ve Sulandırma } \\
\text { Etkisi Dahil Edilmiş } \\
\text { BSM }\end{array}$ & t testi & $\begin{array}{l}\text { Sulandırma etkisinin BSM modeline } \\
\text { dahil edilmesinin modelin fiyatlama } \\
\text { performansını yükselttiği sonucuna } \\
\text { varılmıştır. }\end{array}$ \\
\hline Lekkas (2002) & $\begin{array}{l}\text { Toronto Menkul Kıymetler } \\
\text { Borsası'nda 1982-2002 yılları } \\
\text { arasında işlem gören } 412 \\
\text { hisse senedi varantı }\end{array}$ & $\begin{array}{l}\text { BS ve Sulandırma } \\
\text { Etkisi Dahil Edilmiş } \\
\text { Binomial Model }\end{array}$ & $\mathrm{t}$ testi & $\begin{array}{l}\text { BS modelinin Binomial modele göre daha } \\
\text { etkin olduğu, ancak model ile elde edilen } \\
\text { fiyatların piyasa fiyatlarından önemli } \\
\text { sapmalar gösterdiği sonucuna ulaşılmıştır. }\end{array}$ \\
\hline $\begin{array}{l}\text { Boonchuaymetta } \\
\text { ve Kongtoranin } \\
(2007)\end{array}$ & $\begin{array}{l}\text { Tayland Menkul Kıymetler } \\
\text { Borsası'nda } 2002 \text { yılında } \\
\text { işlem gören } 14 \text { varant }\end{array}$ & $\begin{array}{l}\text { BS, Sulandırma Etkisi } \\
\text { Dahil Edilmiş BS ve } \\
\text { SRCEV }\end{array}$ & * & $\begin{array}{l}\text { Karda ve uzun vadeli olan varantlar için } \\
\text { SRCEV modelinin, zararda ve kısa dönemli } \\
\text { varantlar için BS modelinin üstün olduğu } \\
\text { sonucuna ulaşılmıştır. }\end{array}$ \\
\hline $\begin{array}{l}\text { Jianfeng vd. } \\
\text { (2011) }\end{array}$ & $\begin{array}{l}\text { Şangay ve Shenzhen Menkul } \\
\text { Kıymetler Borsalarında 2005- } \\
2010 \text { yılları arasında işlem } \\
\text { gören } 26 \text { varant }\end{array}$ & $\begin{array}{l}\text { BS, Sulandırma Etkisi } \\
\text { Dahil Edilmiş BS, } \\
\text { SRCEV ve Varyansın } \\
\text { Sabit Esnekliği } \\
\text { Serbest Teta Modelleri }\end{array}$ & t testi & $\begin{array}{l}\text { Varyansın Sabit Esnekliği Serbest Teta } \\
\text { Modelinin en düşük ortalama mutlak } \\
\text { farkları ortaya koyduğu tespit edilmiştir. }\end{array}$ \\
\hline
\end{tabular}

( Not: * Bu çalışmalarda model fiyatları ile piyasa fiyatları arasında oluşan fark istatistiksel olarak test edilmemiştir.)

Yukarıda görüldüğü üzere, varantların işlem gördüğü piyasalarda hangi modelin etkin olduğuna ilişkin çalışmalar literatürde önemli yer bulmuştur. Piyasalar arasında farklılık göstermekle birlikte Varyansın Sabit Esnekliği modelinin genellikle etkin model olduğu, farklı varsayımlarla geliştirilen Black Scholes modellerinin de önemli bir alternatif olduğu belirtilebilir.

\section{OPSIYON FIYATLAMA MODELLERI}

\section{1. Black-Scholes Modeli (BS)}

Black ve Scholes (1973) tarafından, kısa dönem faiz oranlarının bilindiği ve opsiyon vadesi boyunca sabit olduğu, hisse senedi getirilerinin lognormal dağıldığı ve vade boyunca sabit olduğu, opsiyonların Avrupa tipi olduğu gibi bazı varsayımlar (Black ve Scholes, 1973:640) altında alım opsiyonunun fiyatının aşağıdaki formüller aracılığıyla hesaplanabileceği belirtilmektedir.

$$
\begin{aligned}
& C_{n}=S_{n} * N\left(d_{1}\right)-\left(K * e^{-r T}\right) * N\left(d_{2}\right) \\
& d_{1}=\frac{\left(\ln \left(\frac{S}{K}\right)+\left(r+\frac{\sigma^{2}}{2}\right) * T\right)}{\sigma * \sqrt{T}} \\
& d_{2}=d_{1}-(\sigma * \sqrt{T})
\end{aligned}
$$

$\mathrm{Bu}$ formüllerde yer alan $\mathrm{C}$ satın alma opsiyonun bugünkü değerini, $\mathrm{S}$ hisse senedinin (dayanak varlığın) bugünkü değerini (piyasa değerini), K opsiyonun işlem fiyatını, $r$ risksiz faiz oranını, $t$ opsiyonun vadesini, $\sigma$ dayanak varlık getirilerinin standart sapmasını, e $2,71828^{\prime} i$ ve $N\left(d_{1}\right), N\left(d_{2}\right)$ de normal dağılım tablosunda $d_{1}$ ve $d_{2}$ ye karşı gelen değerleri ifade etmektedir.

\subsection{Black-Scholes-Merton Modeli (BSM)}

Hisse senedinin kar payı dağıtması sonucunda değerinde meydana gelecek düşüşün opsiyon fiyatını da etkileyeceği, dolayısıyla Black-Scholes modeline dahil edilmesi gerekliliği Merton (1973) tarafından açıklanmaktadır. q temettü verimini ifade etmek üzere, temettü dağıtımını dikkate alan Black-ScholesMerton Modeli aşağıdaki gibi formülize edilmiştir (Penza ve Bansal, 2001, ss.235-236).

$$
C_{n}=\left(S_{n} * e^{-q T}\right) * N\left(d_{1}\right)-\left(K * e^{-r T}\right) * N\left(d_{2}\right)
$$

$d_{1}=\frac{\left(\ln \left(\frac{S}{K}\right)+\left(r-q+\frac{\sigma^{2}}{2}\right) * T\right)}{\sigma * \sqrt{T}}$

$\mathrm{d}_{2}$ ve diğer terimler yukarıda açıklandığı ifadelere karşılık gelmektedir. 


\subsection{Varyansın Sabit Esnekliği (Constant Elas- ticity of Variance): Karekök (Square Root) Modeli (SRCEV)}

Black-Scholes modelindeki temel varsayım, hisse senedi fiyatlarının lognormal bir dağılıma sahip olduğudur. Cox tarafından 1975 yılında yapılan çalışmada ise hisse senedi fiyat varyanslarının sabit esnekliğe sahip olduğu ortaya konulmuştur. Beckers (1980), Cox(1975) tarafından ortaya konulan bu durumu test ettiği çalışması sonucunda Varyansın Sabit Esnekliği modellerinin Black-Scholes modeline göre daha etkin olduğunu bulmuş ve aşağıdaki formülü Karekök Modeli için önermiştir.

$$
\begin{aligned}
& y=\frac{4 r S}{\sigma^{2}\left(1-e^{-r T}\right)} \\
& z=\frac{4 r K}{\sigma^{2}\left(e^{-r T}-1\right)}
\end{aligned}
$$
üzere;

$w$ parametresi 0 veya 4 değerlerinden birini almak

$$
h(w)=1-\frac{2}{3}(w+y)(w+3 y)(w+2 y)^{-2}(8)
$$$$
q(w)=\frac{\left(1+h(h-1)\left(\frac{w+z y}{(w+y)^{2}}\right)-h(h-1)(2-h)(1-3 h)\left(\frac{(w+z y)^{2}}{2(w+y)^{4}}\right)-\left(\frac{z}{w+y}\right)^{n}\right)}{\left(2 h^{2}\left(\frac{w+2 y}{(w+y)^{2}}\right)(1-(1-h)(1-3 h))\left(\frac{w+2 y}{(w+y)^{2}}\right)\right)^{1 / 2}}
$$

olmak üzere

$$
C=S N(q(4))-K e^{-r T} N(q(0))
$$

\subsection{Binomial Model}

Black-Scholes modeli ile aynı varsayımlara dayanan Binomial Model; hisse senedi fiyatının bir sonraki dönemde belirli bir miktarda artmasına veya azalmasına göre yatırımcının kararlarına yön veren bir modeldir. Model, Cox vd. (1979) tarafından geliştirilmiş̧ir. Modelin teorik alt yapısı aşağıda şematize edilmektedir:

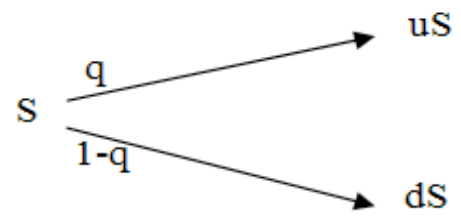

Şekil 1: Dayanak Varlığın Dönem Sonu Değer İhtimalleri Diyagramı
Yukarıdaki şekilde yer alan simgeler;

S: Dayanak varlığın piyasa değeri,

$\mathrm{u}$ : Nakit akışlarının bugünkü değerinin $\mathrm{t}_{1}$ döneminde ne kadar artacağını,

$\mathrm{d}$ : Nakit akışlarının bugünkü değerinin $\mathrm{t}_{1}$ döneminde ne kadar azalacağını,

q: Nakit akışlarının bugünkü değerinin $\mathrm{t}_{1}$ dö neminde artma olasılığını,

1-q: Nakit akışlarının bugünkü değerinin $\mathrm{t}_{1}$ döneminde azalma olasıı̆ı̆ını ifade etmektedir.

$$
\begin{aligned}
& u=e^{\sigma \sqrt{T}} \\
& d=e^{-\sigma \sqrt{T}} \\
& q=\frac{e^{r * T}-d}{u-d}
\end{aligned}
$$

Yukarıdaki formüllerde e 2,71828'i, T vadeye kalan gün sayısını ve $\sigma$ standart sapmayı ifade etmektedir.

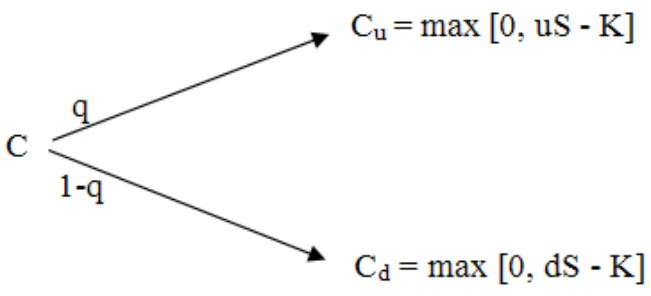

Şekil 2: Opsiyonun Değeri

Dolayısıyla $r$ risksiz faiz oranı ve $\mathrm{K}$ opsiyonun kullanım fiyatını göstermek üzere;

$$
C=\left[C_{u}^{*} q+C_{d}^{*}(1-q)\right] /(1+r)^{\top}
$$

olmaktadır.

\subsection{Diğer Modeller}

Varantların, dayanak hisse senedinin ait olduğu şirket tarafından ihraç edilmeleri, varantın vadesinde kullanılabilir olması durumunda sulandırma etkisi meydana getirmektedir. Galai ve Schneller (1978) yaptıkları çalışmada sulandırma etkisinin modellere nasıl dahil edileceğini açıklamışlardır. Lauterbach ve Schultz (1990) hisse fiyatı yerine firma değerini ve hisse senedi volatilitesi yerine şirketin özkaynak volatilitesini kullanarak ve sulandırma faktörünü belirleyerek sulandırma etkisi dahil edilmiş BlackScholes modelini geliştirmişlerdir. Bazı varantlar için vade tarihinde varantın zararda olması durumunda ihraççı tarafından vadenin uzatılması söz konusu 
olabilmektedir. Longstaff (1990) yaptığı çalışmada vade uzatılabilme durumuna sahip alım varantları için geçerli bir formül sunmuştur. Ayrıca Amerikan tipi opsiyonların fiyatlanmasına ilișkin modellerde geliştirilmiștir (Barone-Adesi ve Whaley, 1987; Bjerksund ve Stensland, 1993; Geske, 1979; Roll, 1977; Whaley, 1981). Ancak bu sayılan modeller, Türkiye piyasası için gerek sulandırma etkisi, gerek vade uzatımı, gerekse Amerikan tipi varant ihracı olmaması nedeniyle uygulama bölümünde değerlendirilmemiştir.

\section{VERILER VE METODOLOJi}

Çalışmada, IMKB'de işlem gören aracı kuruluş varantlarının piyasa fiyatları ile yukarıda açıklanan 4 model (BS, BSM, CEVSR, BINOMIAL) aracılığıyla öngörülen fiyatları karşılaştırılmış ve hangi modelin piyasa fiyatlarını açıklamada üstün olduğu tartışılmıştır. Bu amaca odaklanan çalışmada 2012 yılında IMKB'de işlem görmüş IMKB-30 endeksine dayalı 61 alım varantı $^{2}$ ve bu varantların işlem gördüğü toplam 3.187 gün verisi kullanılmıştır. Veri setini dayanak varlık ve varantların kapanış fiyatları, varantların vadeye kalan süreleri, kullanım fiyatları, dayanak varlığa ilişkin standart sapma değerleri, dayanak varlığın 2009 ile 2011 yılı arasında kalan 3 dönemin ortalama temettü verimi ve risksiz faiz oranlarından ${ }^{3}$ oluşmaktadır.

Modeller için gerekli olan dayanak varlığa ilişkin standart sapmalar, Roon ve Veld (1996) ile Hauser ve Lauterbach (1997) tarafından yapılan çalışmalarda olduğu gibi kullanılmıştır. Her bir model için t-1 gününde, o güne ilişkin değişkenler kullanılarak modelin hesapladığı fiyatı, piyasa fiyatına eşitleyen standart sapmalar, geliştirilen bir program ${ }^{4}$ aracılığıyla her gün için ayrı ayrı bulunmuştur. t gününde ilgili değişkenlerle modellerin varant fiyatını saptamasında ihtiyaç duyulan standart sapmalar t-1 günü için model fiyatı ile piyasa fiyatını eşitleyen değerleriyle kullanılmıştır. ${ }^{5}$ Böylelikle tarihsel standart sapmaların kullanımında ortaya çıkan standart sapmanın hesaplanma döneminin seçilme problemi ortadan kaldırılmış olmaktadır (Veld, 2003:68).

Kullanılan dört modelden her birinin performansı üç indeks aracılığı ile test edilmiştir. Ortalama mutlak fiyatlama hatası (OMFH), piyasa fiyatı ile model tarafındantespitedilenfiyatarasındakimutlakfarkların ortalamasını ifade etmektedir. Diğer indeksler olan ortalama yüzdesel fiyatlama hatası-1 (OYFH(1)) ortalama mutlak fiyatlama hatasının piyasa fiyatına oranı şeklinde (Boonchuaymetta ve Treerapot, 2007:60), ortalama yüzdesel fiyatlama hatası-2 (OYFH(2)) ise ortalama mutlak fiyatlama hatasının model fiyatına oranı şeklinde hesaplanmaktadır (Khelifa ve Abbassi, 2009:6). Hesaplanan indeksler aracılığıyla model- lerin hesapladığı sonuçların piyasa fiyatıyla ve modellerin kendi aralarında karşılaştırılması mümkün olmaktadır. Yalnız indeksler aracılığıyla hesaplanan hataların istatistiksel anlamlılığı önem taşımaktadır. Modelle kullanılarak elde edilen fiyatların birbirlerinden ve piyasa fiyatından farklılaşmasının istatistiksel olarak anlamlı olup olmadığı test etmek için bağımsız (independent) $t$ testi uygulanmış ve hesaplanan $t$ değerine karşılık gelen anlamlılık düzeyinin 0.05 'den küçük olması durumunda model tarafından hesaplanan fiyatların piyasa fiyatlarından istatistiksel olarak anlamlı şekilde farklılaştığı görülmüştür.

$\mathrm{OMFH}=\frac{1}{\mathrm{n}} * \sum_{x=1}^{n}\left|{\text { Piyasa } \text { fiyat }_{\mathrm{x}}-\text { Model Fiyat }}_{\mathrm{x}}\right|$

$\operatorname{OYFH}(1)=\frac{1}{\mathrm{n}} * \sum_{x=1}^{n}\left|\frac{\text { Piyas a fiyat. }_{\mathrm{x}}-\text { Model Fiyat. }_{x}}{\text { Piyasa fiyat. }_{x}}\right|$

$\operatorname{OYFH}(2)=\frac{1}{\mathrm{n}} * \sum_{x=1}^{n}\left|\frac{\text { Piyasa fiyat1 }_{\mathrm{z}}-\text { Model Fiyat }_{\mathrm{z}}}{\text { Model Fiyat }_{\mathrm{s}}}\right|$

Opsiyon fiyatlama modellerinin ampirik çalışmada kullanılış sistematiği aşağıda detaylandırılmıştır:

- Tüm modeller için her bir varantın günlük kastedilen standart sapmalar ayrı ayrı tespit edilmiştir.

- Elde edilen standart sapmalarla birlikte her bir modelde yer alan diğer değişkenler de kullanılarak her bir varantın günlük değer tespitleri ayrı ayrı yapılmıştır.

- Her bir varant için işlem gördüğü günlük piyasa fiyatına IMKB verilerinden ulaşılmıştır.

- Piyasa fiyatları ile her bir model için elde edilen fiyatlar yukarıdaki üç indeks aracılığıyla karşılaştırılmış ve istatistiksel anlamlılığı test edilmiştir.

Çalışmada kullanılan 61 varant Karda/zararda olma durumuna (moneyness) göre karda, zararda ya da başabaşta olmak üzere 3 gruba ayrılmış ve fiyatlama modellerinin geçerliliği her grup için ayrı olarak değerlendirilmiştir. Varantların gruplandırılmasında aşağıdaki formül kullanılmış (Corrado ve Su, 1996:614) ve moneyness faktörü> 0.05 olan varantlar karda, $[-0.05,0.05]$ aralığında olan varantlar başabaş ve $<-0.05$ olan varantlar zararda olarak adlandırılmıştır. Varant gruplarına ilişkin tanımlayıcı istatistikler Tablo 2. de sunulmuştur. 
Tablo 3: Karda Olan Varantlar İçin Dört Alternatif Fiyatlama Modelinin Karşılaştırılması

$$
\text { Moneyness Faktörü }=\frac{\mathrm{S}_{\mathrm{t}}-\mathrm{K}^{-\mathrm{rI}}}{\mathrm{K}^{-\mathrm{rT}}}
$$

Tablo 2: Varant Gruplarına İlişkin Tanımlayıcı İstatistikler

\begin{tabular}{|c|c|c|c|c|c|c|}
\hline & $\begin{array}{c}\text { Varant } \\
\text { Sayısı }\end{array}$ & $\begin{array}{c}\text { Ortalama } \\
\text { Varant } \\
\text { Fiyatı }\end{array}$ & $\begin{array}{c}\text { Vadeye } \\
\text { Kalan } \\
\text { Ortalama } \\
\text { Süre } \\
\text { (Yıl) }\end{array}$ & $\begin{array}{c}\text { Kaldıraç } \\
\text { Düzeyi }\end{array}$ & $\begin{array}{c}\text { Ortalama } \\
\text { Moneyness } \\
\text { Faktörü }\end{array}$ & $\begin{array}{c}\text { Ortalama } \\
\text { Günlük } \\
\text { İşlem } \\
\text { Hacmi } \\
\text { (TL) }\end{array}$ \\
\hline $\begin{array}{c}\text { Karda } \\
\text { Varantlar }\end{array}$ & 22 & 1.77 & 0.1816 & 0.0002 & 0.1361 & 396,511 \\
\hline $\begin{array}{c}\text { Başabaş } \\
\text { Varantlar }\end{array}$ & 26 & 0.71 & 0.1794 & 0.0002 & -0.0027 & 747,011 \\
\hline $\begin{array}{c}\text { Zararda } \\
\text { Varantlar }\end{array}$ & 13 & 0.49 & 0.1539 & 0.0002 & -0.1107 & 191,273 \\
\hline
\end{tabular}

\section{AMPIRIK BULGULAR}

Ampirik bulgular ile dört alternatif opsiyon fiyatlama modeli, Karda/zararda olma durumuna göre karda, başabaş ve zararda olarak ayrılan üç grup için ayrı ayrı karşılaştırılmıştır. Tablo 3'de karda olan alım varantları için modellerin performansına ilişkin sonuçlar gösterilmektedir. Öncelikli olarak bağımsız t testi anlamlılık değerleri incelendiğinde, SRCEV modeli dışındaki modeller için model sonuçları ile piyasa fiyatlarının farklılaştığını ifade eden $\mathrm{H}_{0}$ hipotezi reddedilmiş, dolayısıyla her üç model çıktılarının da piyasa fiyatlarından ve birbirlerinden farklılaşmadığı istatistiksel olarak anlamlı bulunmuştur. Bu nedenle her üç modelin de piyasa fiyatları ile uyumlu fiyatlar tespit ettiği söylenebilir. Üç model içinde, model tarafından bulunan fiyatların piyasa fiyatlarından ortalama mutlak sapması en düşük olan BSM modeli olarak tespit edilmiştir. BSM modeli hem OYFH(1) için hem de $\mathrm{OYFH}(2)$ için en düşük ortalama yüzdesel sapmayı yaratmaktadır. Bu nedenle dört model içerisinde karda olan alım varantlarını fiyatlamada en başarılı modelin BSM modeli olduğu gözlemlenmiştir. Ayrıca model tarafından hesaplanan fiyatların piyasa fiyatından yüksek olma yüzdesini ifade eden pozitif fark yüzdesi BSM modeli için 54.90 olarak hesaplanmış ve modelin tespit ettiği fiyatların piyasa fiyatlarından sapmasının yüksek oranla fazla değerleme (overvalued) şeklinde olduğu sonucuna ulaşılmıştır.

\begin{tabular}{|c|c|c|c|c|c|c|c|c|}
\hline & & & & & $\begin{array}{l}\text { Satır ve } \\
\text { eller Ar } \\
\text { Fiyatlar }\end{array}$ & $\begin{array}{l}\text { ütunlar } \\
\text { sındaki } \\
\text { a Farkla }\end{array}$ & $\begin{array}{l}\text { la Yer Al } \\
\text { rtalam }\end{array}$ & $\begin{array}{l}\text { n Mod- } \\
\text { Mutlak }\end{array}$ \\
\hline & OMFH & OYFH(1) & OYFH(2) & $\begin{array}{l}\text { Pozitif fark } \\
\text { yüzdesi }\end{array}$ & BS & BSM & SRCEV & $\begin{array}{l}\text { BINO- } \\
\text { MIAL }\end{array}$ \\
\hline BS & $\begin{array}{l}0.05 \\
(0.936)\end{array}$ & 0.0318 & 0.0322 & 49.60 & - & & & \\
\hline BSM & $\begin{array}{l}0.04 \\
(0.923) \\
\end{array}$ & 0.0293 & 0.0296 & 54.90 & $\begin{array}{l}0.01 \\
(0.859) \\
\end{array}$ & - & & \\
\hline SRCEV & $\begin{array}{l}0.57 \\
(0.000)\end{array}$ & 0.5244 & 0.5806 & 39.00 & $\begin{array}{l}0.52 \\
(0.000)\end{array}$ & $\begin{array}{l}0.53 \\
(0.000)\end{array}$ & - & \\
\hline $\begin{array}{l}\text { BINO- } \\
\text { MIAL }\end{array}$ & $\begin{array}{l}0.05 \\
(0.791)\end{array}$ & 0.0350 & 0.0353 & 43.18 & $\begin{array}{l}0.00 \\
(0.854)\end{array}$ & $\begin{array}{l}0.01 \\
(0.718)\end{array}$ & $\begin{array}{l}0.52 \\
(0.000)\end{array}$ & - \\
\hline
\end{tabular}
anlamlıık düzeyini ifade etmektedir.)

Başabaş olan varantlar için etkin olan modelin belirlenmesini sağlamak amacıyla elde edilen bulgular Tablo 4'de gösterilmektedir. Başabaş varantlar için de karda olan varantlara benzer şekilde SRCEV modeli dışındaki üç modelin her biri ile elde edilen fiyatların piyasa fiyatlarından farklılaşmadığı istatistiksel olarak anlamlı bulunmuştur. Üç model içinde BS ve BSM modellerinin OMFH'na göre farklılaşmadığı ve en düşük ortalama mutlak hatayı verdikleri gözlemlenmektedir. Yüzdesel hatalara bakıldığında ise OYFH(1) için BSM modeli, OYFH(2) içinse BS modelinin piyasa fiyatlarından daha az sapma oluşturduğu tespit edilmiştir. Fakat yüzdeler arasındaki farkın düşük olması, ayrıca İMKB'de işlem gören varantlar için en küçük fiyat aralığının kuruş düzeyinde olması, dolayısıyla bu küçük yüzdesel farkın fiyatlarda açıklanamaması iki model arasında seçim yapmayı olanaksızlaştırmaktadır. BS ve BSM modelleri ile piyasa fiyatları arasında gözlemlenen sapmaların ise sırasıyla yüzde 50.22 ve 50.66 oranında fazla değerleme şeklinde olduğu tespit edilmiştir.

Tablo 4: Başabaş Olan Varantlar İçin Dört Alternatif Fiyatlama Modelinin Karşılaştırılması

\begin{tabular}{|l|l|l|l|l|l|l|l|l|}
\hline \multicolumn{7}{|c|}{} & \multicolumn{3}{|l|}{$\begin{array}{l}\text { Satır ve Sütunlarda Yer Alan Mod- } \\
\text { eller Arasındaki Ortalama Mutlak } \\
\text { Fiyatlama Farkları }\end{array}$} \\
\hline & OMFH & OYFH(1) & OYFH(2) & $\begin{array}{l}\text { Pozitif } \\
\text { f a r k } \\
\text { yüzdesi }\end{array}$ & BS & BSM & SRCEV & $\begin{array}{l}\text { B I - } \\
\text { N O - } \\
\text { MIAL }\end{array}$ \\
\hline BS & $\begin{array}{l}0.03 \\
(0.942)\end{array}$ & 0.0522 & 0.0523 & 50.22 & - & & & \\
\hline BSM & $\begin{array}{l}0.03 \\
(0.963)\end{array}$ & 0.0521 & 0.0527 & 50.66 & $\begin{array}{l}0.00 \\
(0.979)\end{array}$ & - & & \\
\hline SRCEV & $\begin{array}{l}0.78 \\
(0.000)\end{array}$ & 1.3318 & 1.3464 & 48.53 & $\begin{array}{l}0.75 \\
(0.000)\end{array}$ & $\begin{array}{l}0.75 \\
(0.000)\end{array}$ & - & \\
\hline $\begin{array}{l}\text { BINO- } \\
\text { MIAL }\end{array}$ & $\begin{array}{l}0.04 \\
(0.864)\end{array}$ & 0.1046 & 0.1464 & 50.29 & $\begin{array}{l}0.01 \\
(0.922)\end{array}$ & $\begin{array}{l}0.01 \\
(0.901)\end{array}$ & $\begin{array}{l}0.73 \\
(0.000)\end{array}$ & - \\
\hline \\
(Not: Parantez içinde yer alan değerler bağımsız t testi için t değerine \\
karşוlık gelen anlamlılık düzeyini ifade etmektedir.)
\end{tabular}

Zararda olan alım varantları için dört opsiyon fiyatlama modeli karşılaştığında sonuçların başabaş olan varantlarla benzer olduğu tespit edilmiştir (Tablo5). BS ve BSM modelleri ortalama mutlak hatalar açısından farksız iken, ortalama yüzdesel 
hatalar bakımından BSM modeli daha üstün olarak bulunmuştur. Fakat yüzdesel hatalar arasındaki farkın kuruş düzeyinde bir ayrışmayı açıklayabilecek düzeyde büyük olmaması modeller arasında tercih yapılamamasına neden olmaktadır. BS ve BSM modelleri ile elde edilen fiyatların piyasa fiyatlarından farklılaşan sırasıyla yüzde 48.33 ve $48.93^{\prime}$ lük kısmının fazla fiyatlamadan kaynaklandığı sonucuna ulaşılmıştır.

Tablo 5: Zararda Olan Varantlar İçin Dört Alternatif Fiyatlama Modelinin Karşılaştırılması

\begin{tabular}{|l|l|l|l|l|l|l|l|l|}
\hline & & & & \multicolumn{5}{|c|}{$\begin{array}{l}\text { Satır ve Sütunlarda Yer Alan } \\
\text { Modeller Arasındaki Ortalama } \\
\text { Mutlak Fiyatlama Farkları }\end{array}$} \\
\hline & OMFH & OYFH(1) & OYFH(2) & $\begin{array}{l}\text { Pozitif } \\
\text { fark } \\
\text { yüzdesi }\end{array}$ & BS & BSM & SRCEV & $\begin{array}{l}\text { BINO- } \\
\text { MIAL }\end{array}$ \\
\hline BS & $\begin{array}{l}0.02 \\
(0.987)\end{array}$ & 0.0988 & 0.3672 & 48.33 & - & & & \\
\hline BSM & $\begin{array}{l}0.02 \\
(0.993)\end{array}$ & 0.0945 & 0.3550 & 48.93 & $\begin{array}{l}0.00 \\
(0.994)\end{array}$ & - & & \\
\hline SRCEV & $\begin{array}{l}0.35 \\
(0.000)\end{array}$ & 0.8737 & 0.6098 & 40.71 & $\begin{array}{l}0.33 \\
(0.000)\end{array}$ & $\begin{array}{l}0.33 \\
(0.000)\end{array}$ & - & \\
\hline $\begin{array}{l}\text { BINO- } \\
\text { MIAL }\end{array}$ & $\begin{array}{l}0.05 \\
(0.933)\end{array}$ & 0.4782 & 0.2633 & 45.95 & $\begin{array}{l}0.03 \\
(0.920)\end{array}$ & $\begin{array}{l}0.03 \\
(0.926)\end{array}$ & $\begin{array}{l}0.30 \\
(0.000)\end{array}$ & - \\
\hline
\end{tabular}

(Not: Parantez içinde yer alan değerler bağımsız $t$ testi için $t$ değerine karşılık gelen anlamlılık düzeyini ifade etmektedir.)

\section{SONUÇ}

Çalışmada dört opsiyon fiyatlama modelinden hangisinin piyasa fiyatlarına daha yakın sonuçlar verdiği, dolayısıyla etkin yöntem olduğu araştırıımıştır. Karda olan alım varantları için BSM modeli piyasa fiyatlarına en yakın fiyatları sunduğundan etkin model olarak belirlenirken, başabaş ve zararda olan alım varantları için BS ve BSM modelleri arasında bir tercih yapılamamıştır. Binomial model ile elde edilen fiyatlar ile piyasa fiyatlarının her üç varant grubu için de farklılaşmadığı istatistiksel olarak anlamlı bulunmasına rağmen piyasa modelin hesapladığı varant fiyatlarının piyasa fiyatlarından ortalama mutlak sapmalarının BS ve BSM modellerine göre yüksek olması bu modelin etkin olarak tercih edilmemesine neden olmuştur. SRCEV modeli ile elde edilen varant fiyatlarının ise her üç varant grubunda da hem piyasa fiyatlarıyla hem de diğer modeller tarafından bulunan fiyatlarla farklılaştığı istatistiksel olarak anlamlı bulunmuştur. Dolayısıyla literatürde yer alan bazı çalışmaların ( Lauterbach ve Schultz, 1990; Shastri ve Sirodom, 1995; Hauser ve Lauterbach, 1997; Boonchuaymetta ve Treerapot, 2007) aksine SRCEV modelinin varant fiyatlarını açıklamada etkin bir yöntem olmadığı ortaya konulmuştur.

IMKB'de işlem gören aracı kurum varantlarında, likiditeyi sağlamak amacıyla aracı kurumlar piyasa yapıcılık faaliyeti sunmaktadır. Bu nedenle piyasa fiyatları aracı kurumlar tarafından oluşturulan fiyat kotasyonları aralığında gerçekleşmektedir. Gün içerisinde piyasada oluşan talebe göre fiyat kotasyonlarında değişme olmasına rağmen, piyasa yapıcının fiyatlamada etkin olduğu söylenebilir. 2012 yılı için varant ihraç eden iki aracı kurumdan biri, fiyat tespitinde BSM modelini tercih ettiğini belirtmektedir. Ayrıca BS modeli, BSM modelinden sadece temettü verimini modele dahil etmeyerek farklılaştığından ve IMKB 30 endeksine ait ortalama temettü veriminin kuruş düzeyindeki varant fiyatlarını etkileyecek kadar yüksek değerlerde olmadığından bu modelde BSM modeli ile birlikte etkin olmaktadır. Çalışma sonucunda etkin model olarak BS ve BSM modellerinin tespit edilmesinde bu durumunda etkili olduğu söylenebilir.

IMKB'de işlem gören aracı kurum varantlarında kaldıracın aracı kurumlar tarafından düşük büyük oranda 0.0002 ) tutulmasının yanında fiyat adımlarının kuruş düzeyinde belirlenmesi BS ve BSM modelleri arasında tercih yapmayı zorlaştırmaktadır. Bu nedenle yatırımcıların daha etkin karar verebilmelerini sağlamak amacıyla varantlarda fiyat adımlarının kuruş altında belirlenebilmesi sağlanmalıdır. 


\section{SON NOTLAR}

${ }^{1}$ Etkin model ile kastedilen; model tarafindan hesaplanan günlük varant fiyatları ile piyasada oluşan varant fiyatları arasındaki ortalama mutlak farkı minimum yapan modeldir. Ayrıca bu farkın istatistiksel olarak anlamlı olması da önem taşımaktadır.

22012 yilında İMKB'de piyasaya sunulan 4 adet İMKB-30 endeksine dayalı aracı kuruluş varantı ise işlem görmediği, 2 varant ise kaldıraç dereceleri farklı olduğu için çalışmanın veri setine dahil edilmemiştir. Varantların ve dayanak varlığın günlük kapanış fiyatları ve işlem hacimleri İMKB'nin resmi sitesi olan www.imkb.gov.tr adresinden sağlanmıştır.

${ }^{3}$ Risksiz faiz oranları, T.C.Hazine Müsteşarlığı’nın iç borçlanma aylık ortalama maliyeti yıllık veriye çevrilerek kullanılmış ve ilgili veriler www.hazine.gov.tr adresinden sağlanmıştır.

${ }^{4}$ JAVA programlama dili ile yazılan program, model fiyatlarını piyasa fiyatlarına eşitleyen standart sapmaları deneme yanılma yöntemiyle bulmuştur. Programın geliştirilmesinde sağladığı katkılardan dolayı TÜBİTAK Uzay Enstitüsü Uzman Araştırmacısı Mashar TEKIN'e teşekkür ederiz.

5 Varantların piyasa fiyatlarının modellerin alt limitlerinin daha altında veya üst limitlerinin daha üstünde olduğu durumlarda piyasa fiyatı ile model fiyatını eşitleyen bir standart sapma bulunamayacağından dolayı bu günlere ait varant verileri veri setine dahil edilmemiştir.

\section{KAYNAKLAR}

Barone-Adesi, G. ve Whaley, R.E. (1987) "Efficient Analytic Approximation of American Option Values" The Journal of Finance, 42(2):301-320.

Beckers, S. (1980) "The Constant Elasticity of Variance Model and Its Implications For Option Pricing" The Journal of Finance, 35(3):661-673.

Bjerksund, P., Stensland, G. (1993) "Closed-Form Approximation of American Options" Scandinavian Journal of Management, 9(1):87-99.

Black, F. ve Scholes, M.S. (1973) "The Pricing of Options and Corporate Liabilities" Journal of Political Economy, 81(3):637-654.

Boonchuaymetta, E. ve Kongtoranin, T. (2007) "Warrant Pricing Model: An Empirical Study on the Valuation Models for Warrants Listed in Thailand" $A U$ Journal of Management, 5(2):56-66.

Chen, K.C., Shahrokhi, M. ve Wilson, J. (1997) "Pricing Financial Times-Stock Exchange Index Warrants" American Business Review, 22(2): 44-51.

Corrado, C.J. ve Su, T. (1996) "S\&P 500 INDEX Option Tests of Jarrow and Rudd's Approximate Option Valuation" The Journal of Futures Markets, 16(6): 611629.

Cox, J.C., Ross, S.A. ve Rubinstein, M. (1979) "Option Pricing: A Simplified Approach" Journal of Financial Economics, 7(3):229-263.
Frino, A., Khan, E. ve Lodh, S.C. (1991) "The Black Scholes Call Option Pricing Model and the Australian Options Market: Where Are We After 15 Years" University of Wollongong, Accounting \& Finance Working Paper, No:91/24.

Galai, D., Schneller, M.I. (1978) "Pricing of Warrants and The Value of The Firm" The Journal of Finance, 33(5):1333-1342.

Geske, R. (1979) "The valuation of compound options" Journal of Financial Economics, 7(1):63-81.

Hauser, S., Lauterbach, B. (1997) “The Relative Performance of Five Alternative Warrant Pricing Models" Financial Analysts Journal, 53(1):55-61.

Jianfeng, Z., Wenxiu, H. ve Li, Z. (2011) “The Relative Performance of Four Alternative Warrant Pricing Models: A Study of the Chinese Warrant Markets" System Science Engineering Design and Manufacturing Informatization (ICSEM), International Conference, 22-23 October.

Khelifa, Z.B. ve Abbassi, W. (2009) "Pricing Warrants Models: An Empirical Study of The Indonesian Market" 5ème Conférence Internationale de Finance, 12-13-14 March, Hammamet, Tunisie.

Kremer, J.W. ve Roenfeldt, R.L. (1993) "Warrant Pricing: Jump-Diffusion vs. Black-Scholes" The Journal of Financial and Quantitative Analysis, 28(2):255-272. Wiley. 
Kuwahara, H. ve Marsh, T.A. (1992) "The Pricing of Japanese Equity Warrants" Management Science, 38(11):1610-1641.

Lauterbach, B. ve Schultz, P. (1990) "Pricing Warrants: An Empirical Study of the Black-Scholes Model and Its Alternatives" The Journal of Finance, 45(4):1181-1209.

Lekkas, G. (2002) "Option Pricing in the Presence of Warrants" Master Thesis, Condordia University, John Molson School of Business, School of Graduate Studies.

Longstaff, F. (1990) "Pricing Options with Extendible Maturities: Analysis and Applications" Journal of Finance, 45(3):935-57.

Mayo, H.B. (2010) Investments: An Introduction, USA, South-Western College Publucation.

Merton, R.C. (1973) "Theory of Rational Option Pricing" The Bell Journal of Economics and Management Science, 4(1):141-183.

Noreen, E. ve Wolfson, M. (1981) "Equilibrium Warrant Pricing Models and Accounting for Executive Stock Options" Journal of Accounting Research, 19(2):384398.

Penza, P. ve Bansal, V.K. (2001) Measuring Market Risk with Value at Risk, USA, Wiley.
Roll, R. (1977) "An Analytical Formula for Unprotected American Call Options on Stocks with Known Dividends" Journal of Financial Economics, 5(2):251-258.

Roon, F. ve Veld, C. (1996) "An Empirical Investigation of The Factors That Determine The Pricing of Dutch Index Warrants" European Financial Management, 2(1):97-112.

Santoso, L.E. (2000) "Warrant Pricing: An Empirical Investigation On The Valuation Models For Warrants Traded At The Jakarta Stock Exchange" Master Thesis, Gadjah Mada University, Program of Graduate Studies.

Shastri, K. ve Sirodom, K. (1995) "An Empirical Test of The BS and CSR Valuation Models for Warrants Listed in Thailand" Pacific-Basin Finance Journal, 3(4):465-483.

Veld, C. (2003) "Warrant Pricing: A Review of Empirical Research" The European Journal of Finance, 9(1):61-91.

Whaley, R.E. (1981) "On the valuation of American Call Options on Stocks With Known Dividends" Journal of Financial Economics, 9(2):207-211. 
